\title{
Repositie van supracondylaire humerusfracturen middels een tijdelijke Kirschner-draad
}

S. Moerman1, F.E. Buisman2, P.R. Schütte3, B.J. Punt4

1 aios orthopedie, afdeling Orthopedie, Erasmus Medisch Centrum, Rotterdam

2 anios chirurgie, afdeling Chirurgie, Erasmus Medisch Centrum, Rotterdam

3 oud chirurg, voorheen afdeling Chirurgie, Albert Schweitzer Ziekenhuis, Dordrecht

4 traumachirurg, afdeling Chirurgie, Albert Schweitzer Ziekenhuis, Dordrecht

\section{Samenvatting}

Instabiele gedislokeerde supracondylaire humerusfracturen bij kinderen worden in opzet behandeld met gesloten repositie en fixatie middels Kirschner-draden. Het functionele resultaat is mede afhankelijk van een adequate repositie. Deze repositie kan met de conventionele repositiemethode lastig zijn bij deze soms multidirectioneel instabiele fracturen bij jonge kinderen. Het artikel beschrijft, aan de hand van een casus, een methode waarbij gebruik wordt gemaakt van een tijdelijke Kirschner-draad in het proximale humerusfragment. Zodra, middels manipulatie, de adequate repositie is bereikt wordt de fractuur op de gebruikelijke manier gefixeerd en de tijdelijke Kirschner-draad verwijderd. Deze techniek zou kunnen bijdragen aan het verkleinen van het aantal conversies naar een open repositie.

\section{Inleiding}

De supracondylaire humerusfractuur is de frequentst voorkomende fractuur van de elleboog bij kinderen. $18 \%$ van alle fracturen op kinderleeftijd zijn supracondylaire humerusfracturen. ${ }^{1}$ Deze fracturen hebben een piekincidentie op de leeftijd van 5 tot 7 jaar. ${ }^{2}$ Het traumamechanisme is vaak een val van hoogte met een uitgestrekte hand en elleboog. Daarbij wigt de dorsale zijde van de distale humerus op het olecranon en fractureert de humerus aan de volaire zijde. De musculus triceps trekt het distale fragment naar dorsaal, waardoor het proximale deel van de humerus volair in de weke delen steekt. Supracondylaire humerusfracturen worden van oudsher ingedeeld volgens de classificatie van Gartland. ${ }^{3}$ Type I-fracturen zijn de niet-gedislokeerde fracturen; type II-fracturen zijn gedislokeerd waarbij de posterieure cortex intact is en type III-fracturen zijn de volledig gedislokeerde fracturen. Tegenwoordig wordt daar soms nog een type IV aan toegevoegd, wat de fracturen zijn met complete periostale disruptie, waardoor deze zowel in flexie als in extensie instabiel zijn. De type III- en IV-fracturen, waarbij het distale fragment naar posterieur dislokeert, hebben een groot 
risico op letsel van de weke delen. Bij 8-10\% van de kinderen met een gedislokeerde supracondylaire humerusfractuur is er sprake van het wegvallen van de pulsaties in de pols. Daarbij heeft het kind een koude witte hand. Wanneer een pulsoximeter wordt aangesloten op de ipsilaterale vingers is de saturatie lager. ${ }^{4}$ Dislocatie van het distale fragment naar posterolateraal zorgt voor een relatieve verplaatsing van het proximale fragment naar anteromediaal. Dit geeft risico op tractie en daarbij soms ook schade van de arteria brachialis en daarmee het risico op trombose en ischemie. Dit risico is echter beperkt, gezien de uitgebreide collaterale circulatie. $\mathrm{Na}$ repositie herstelt de circulatie bij ruim $90 \%$ van deze patiënten.

Daarnaast is er bij 10-30\% van de supracondylaire humerusfracturen sprake van zenuwletsel. 5 Een posterolaterale luxatie geeft risico op letsel van de nervus medianus of letsel van zijn aftakking, de nervus interosseus anterior (AIN). Letsel van de nervus medianus of de AIN representeert $50 \%$ van al het zenuwletsel bij een supracondylaire hume- rusfractuur. Posteromediale dislocatie geeft risico op letsel van de nervus radialis en bij een supracondylaire humerusfractuur van het flexietype is de nervus ulnaris potentieel bedreigd. Het grootste deel van het zenuwletsel betreft neuropraxie, die spontaan herstelt binnen zes maanden. ${ }^{6}$ Gartland type I-fracturen worden conservatief behandeld middels bovenarmgips. Gartland type II-, III- en IV-fracturen worden behandeld met gesloten repositie en interne fixatie met een twee- of drietal Kirschner-draden. ${ }^{7}$ De Kirschner-draden kunnen gekruist (zowel van mediaal als lateraal) of beide van lateraal worden ingebracht. Er wordt beschreven dat gekruiste Kirschner-draden meer rotatiestabiliteit geven, echter, bij het inbrengen van een mediale Kirschner-draad is er kans op iatrogene schade van de nervus ulnaris. 8 Inadequate repositie kan leiden tot verlies van functie door deformaties, zoals varus- en valgus- deformatie, malrotatie, angulatie en translatie. ${ }^{9}$ Indien er via de gesloten procedure geen adequate repositie wordt verkregen, moet er worden geconverteerd naar een open procedure. Er worden con- versiepercentages van 3-46\% beschreven. Een retrospectieve studie vergeleek 22 Gardland type III-fracturen, behandeld met een gesloten repositie, met 23 fracturen die open moesten worden gereponeerd omdat gesloten repositie faalde. Dit gebeurde via een posterieure benadering. De open gereponeerde fracturen hadden een iets langere tijd tot union, de extensiebeperking na de open procedure was 6 graden en na de gesloten procedure 1 graad. Een samengestelde maat voor zowel de afwijking van de varus-valgushoek als de flexie-extensiebeperking zijn de Flynn-criteria. Open repositie leidt volgens deze criteria in $29 \%$ en gesloten repositie in $5 \%$ van de gevallen tot een matig of slecht resultaat. Ook is de cosmetiek na een open repositie over het algemeen minder fraai. ${ }^{10} \mathrm{Bij}$ deze 
resultaten moet worden aangetekend dat de open repositie vaker geschiedt bij patiënten met een lastiger fractuur.

In de afgelopen decennia hebben diverse auteurs vele methoden beschreven om gedislokeerde supracondylaire humerusfracturen te reponeren.
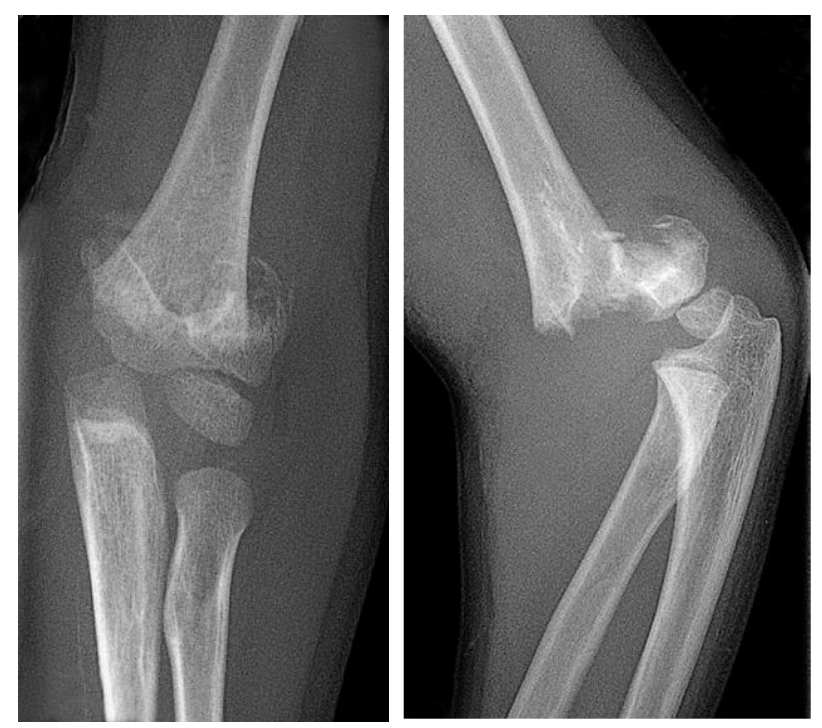

Figuur 1. Röntgenopname anterior-posterior (links) en lateraal (rechts) van de gedislokeerde supracondylaire humerusfractuur Gardland type III.

Deze methoden verschillen onder andere in de stand van de elleboog bij repositie. Zo wordt zowel volledige extensie, 60 graden flexie en 90 graden flexie beschreven. Ook worden zowel rug- als buikligging benoemd. ${ }^{11,12}$ Chen et al. verrichtten een gerandomiseerde trial waarbij het resultaat van repositie in 90 graden flexie en repositie in exten- sie werden vergeleken. Hieruit bleek dat in exten- sie reponeren betere klinische resultaten geeft. Bij repositie in extensie werd na een follow-up van 4,6 jaar geen cubitus varus gezien en bij repositie in flexie had $60 \%$ van de kinderen een cubitus varus. 13

Parmaksizoglu et al. beschreven een methode waar- bij de rotatie en translatie gemakkelijker gecorri- geerd kunnen worden door een Kirschner-draad te plaatsen in het proximale fragment. De patiënt ligt hierbij in rugligging. ${ }^{14}$ Recentelijk is er ook een methode beschreven door Novais et al., waarbij er gesloten reductie plaatsvindt met een joystick in het distale fragment. 15

In de casus die wij hier beschrijven wordt een combinatie van deze methoden gebruikt voor het gesloten reponeren van Gartland type III- en IV-supracondylaire humerusfracturen.

\section{Casus}


Een zesjarige patiënt presenteerde zich op de Spoedeisende Hulp (SEH) nadat hij op het school- plein op zijn linkerarm was gevallen. De patiënt had forse pijn en een afwijkende stand van de linkerelleboog. Hij is rechts dominant en verder goed gezond. Bij lichamelijk onderzoek waren de nervus radialis, ulnaris en medianus intact en waren er goede pulsaties van de arteria radialis en ulnaris. De hand was roze en de saturatie gemeten aan de vinger was $100 \%$. De röntgenopname toon- de een Gartland type III-supracondylaire hume- rusfractuur met dislocatie van het distale fragment naar dorsaal (Fig. 1).

De patiënt werd dezelfde dag onder algehele anesthesie in buikligging geopereerd. De linkerschouder van de patiënt werd op de rand van de ope- ratietafel gelegd. De bovenarm werd vervolgens op een vierkant röntgendoorlaatbaar armsteuntje geplaatst zodat de onderarm kon afhangen (Fig. 2). Daarna werd de arm steriel afgedekt. Een gesloten repositiepoging middels lengtetractie, flexie en pro- en supinatie leidde tot een onvoldoende goede repositie. De poging tot gesloten repositie is nog tweemaal herhaald zonder een acceptabel resultaat te behalen. Daarom werd een tijdelijke $2 \mathrm{~mm}$ dikke Kirschner-draad ter hoogte van de mid- schacht humerus vanuit lateraal geplaatst (Fig. 3). Deze plaats werd gekozen om weg te blijven uit het verloop van de nervus radialis. De Kirschner-draad werd gebruikt als joystick om controle te houden over het proximale fragment. Door manipulatie van de joystick werd de rotatie van de humerus onder röntgendoorlichting gecorrigeerd. De fractuur werd met gekruiste Kirschner-draden gefixeerd. Aangezien stabiliteit na twee Kirchner-draden niet als voldoende werd beoordeeld, werd er een derde draad vanuit mediaal bijgeplaatst. Vervolgens werd de joystick verwijderd.

De patiënt werd zes weken nabehandeld met bovenarmgips en een mitella. Na zes weken werden de Kirschner-draden verwijderd. De bereikte correctie wordt getoond in Fig. 3 (peroperatief) en in Fig. 4 (vijf weken postoperatief). Na drie maanden werd de patiënt teruggezien voor controle op de polikliniek. Fig. 5 toont de range of motion drie maanden postoperatief. De patiënt had op dat moment nog een lichte functiebeperking (flexie/ extensie 155/5/0 graden; carrying angle 5 graden). De behandelingen door de fysiotherapeut werden gecontinueerd. 


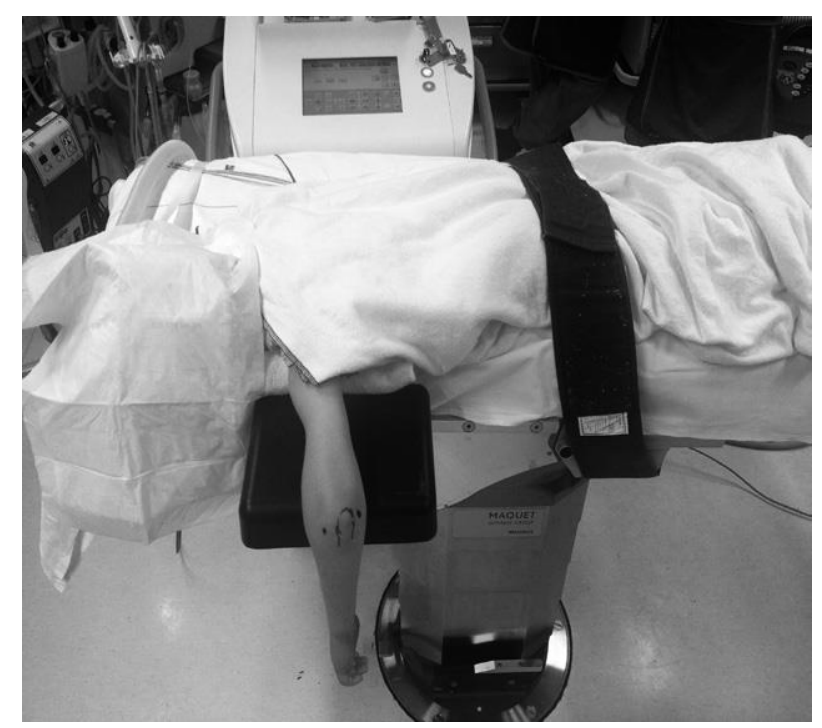

Figuur 2. De patiënt op de OK in buikligging.

\section{Bespreking}

Het verkrijgen van rotatiecorrectie bij supracondylaire humerusfracturen is belangrijk voor de functionele uitkomst van deze fracturen bij kin- deren. ${ }^{9}$ De conventionele operatieve behandeling van complexe supracondylaire humerusfracturen bestaat uit een gesloten repositie en fixatie. Wij beschrijven een methode waarbij de repositie geschiedt in buikligging. Daarbij wordt in geval van onvoldoende resultaat van de gesloten reposi- tie een tijdelijke Kirschner-draad vanuit lateraal in het proximale fragment geplaatst. Hiermee wordt het proximale fragment gemanipuleerd voor het verkrijgen van goede rotatiecorrectie. Deze metho- de zou een conversie naar een open procedure kunnen voorkomen. Bij de behandeling van supracondylaire humerus- fracturen wordt zowel positionering in rug-, buik- als zijligging toegepast. In alle drie deze posities kan de tijdelijke Kirschner-draad in het proximale fragment worden gebruikt als hulpmiddel. In de gepresenteerde casus was de eerste gesloten repositiepoging niet succesvol. Repositie geschied- de middels lengtetractie, flexie en pro- en supina- tie. Er zijn vele methoden voor gesloten repositie en uiteraard dient de repositie te worden aangepast aan de dislocatierichting van de fractuur zoals op de doorlichtingsopname te zien is. In onze ervaring kan dit zowel in rug- als buikligging lastig zijn bij jonge kinderen, omdat het bovenarmpje vaak kort en mollig is. Controle over het proximale fragment kan dan helpen. De fixatie heeft in deze casus plaats- gevonden middels drie Kirschner-draden, waarbij er twee vanuit ulnair zijn geplaatst. Het heeft onze voorkeur één Kirschner-draad vanuit ulnair en één vanuit radiair te plaatsen, echter, in deze casus was de stabiliteit op dat moment niet voldoende. Een extra Kirschner-draad vanuit ulnair geeft uiteraard een extra risico op letsel van de nervus ulnaris. Parmaksizoglu et al. beschrijven een soortge- lijke joystickmethode met het plaatsen van een Kirschner-draad in het proximale fragment. Zij volgden 23 kinderen die 
op deze wijze gereponeerd werden. De functionele uitkomsten, gemeten met behulp van de Flynn-criteria, waren bij een follow- up van twee jaar bij $90 \%$ van de kinderen excellent en bij $4 \%$ goed. ${ }^{14}$ Novais et al. beschrijven een methode waarbij gebruik wordt gemaakt van een Kirschner-draad in het capitulum. ${ }^{15}$ De Kirschner-draad wordt, na het verkrijgen van rotatiecorrectie, doorgeboord in de proximale mediale cortex. Daarna wordt er een tweede Kirschner-draad vanaf lateraal bijgeplaatst ter stabilisatie. Ook zij zagen goede uitkomsten en geen complicaties bij de acht onderzochte kinderen.
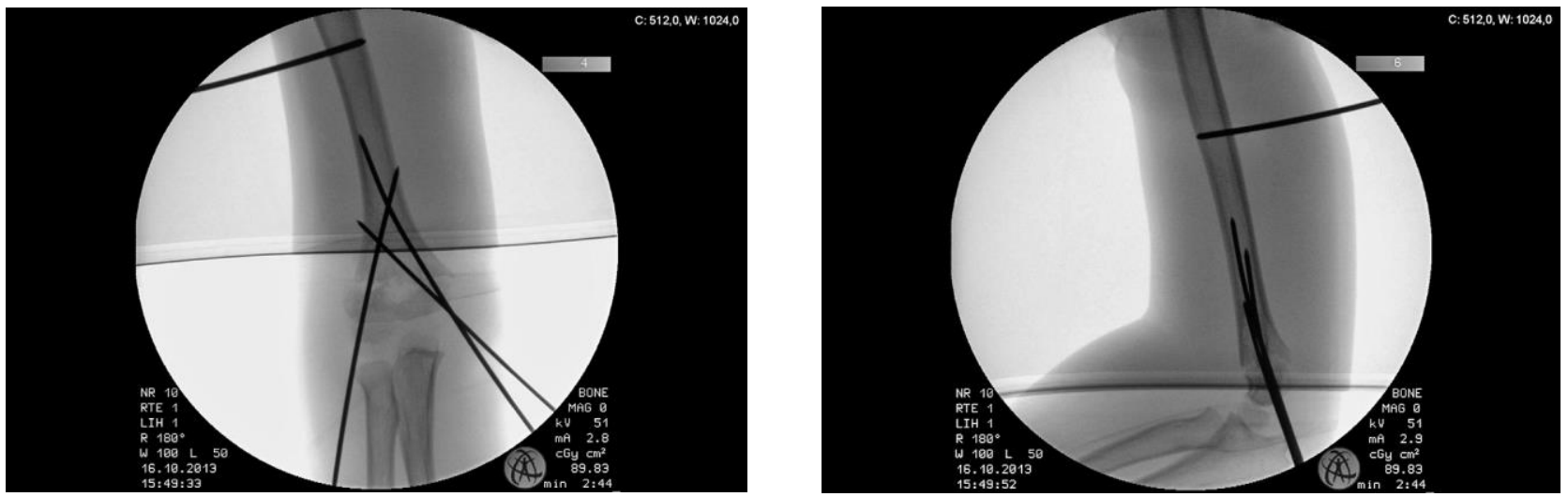

Figuur 3. Peroperatieve doorlichting anterior-posterior (links) en lateraal (rechts) met gebruikmaking van een tijdelijke 2,0 mm dikke Kirschner-draad.
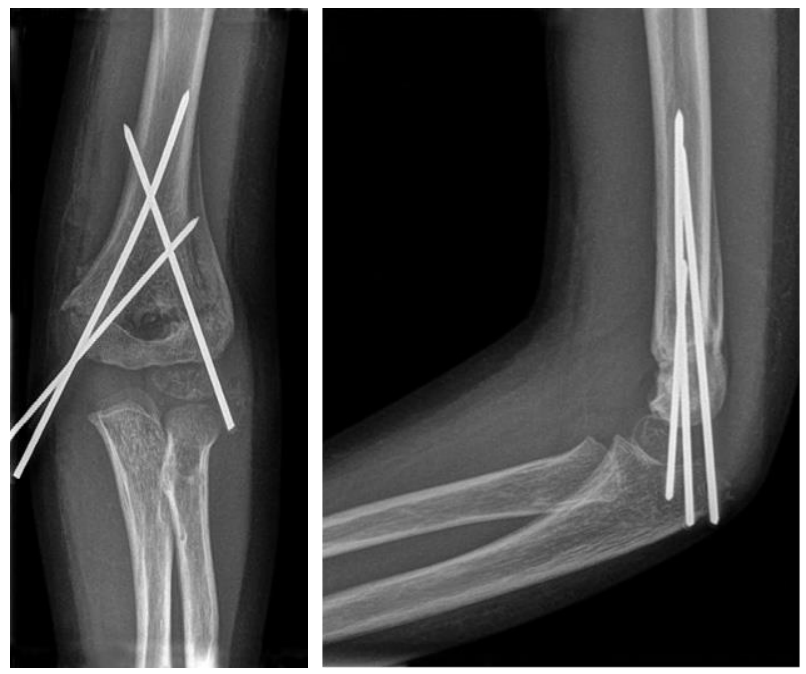

Figuur 4. Röntgencontrole vijf weken postoperatief anterior-posterior (links) en lateraal (rechts).

Rotatiecorrectie van het proximale fragment met een tijdelijke Kirschner-draad door de humerus is een eenvoudig hulpmiddel wanneer de reposi- tie peroperatief lastig is. De methode kan worden toegepast in zowel rug- als buikligging. Het kan conversie naar een open repositie en de daarbij behorende complicaties voorkomen. Bovendien kan, zoals beschreven door Parmaksizoglu et al., de operatietijd en doorlichtingstijd hiermee wor- den 
verkort. ${ }^{14}$ Een eventueel nadeel van deze methode is het risico op schade aan de neurovasculaire structuren in de proximale humerus. Dit risico dient geminimaliseerd te worden door de Kirschner-draad lateraal en in het middelste derde deel te plaatsen, om de nervus radialis niet te benaderen.

\section{Conclusie}

Deze casus beschrijft een zesjarige patiënt met een gedislokeerde supracondylaire humerusfractuur. Na een drietal onsuccesvolle gesloten repositie- pogingen werd een tijdelijke Kirschner-draad in het proximale fragment geplaatst. De gesloten reposi- tiemethode middels de tijdelijke Kirschner-draad, zoals beschreven in dit artikel, is een eenvoudig hulpmiddel voor de behandeling van gedislokeerde supracondylaire humerusfracturen. Mogelijk kan het conversiepercentage naar een open repositie hiermee.verlaagd.worden.
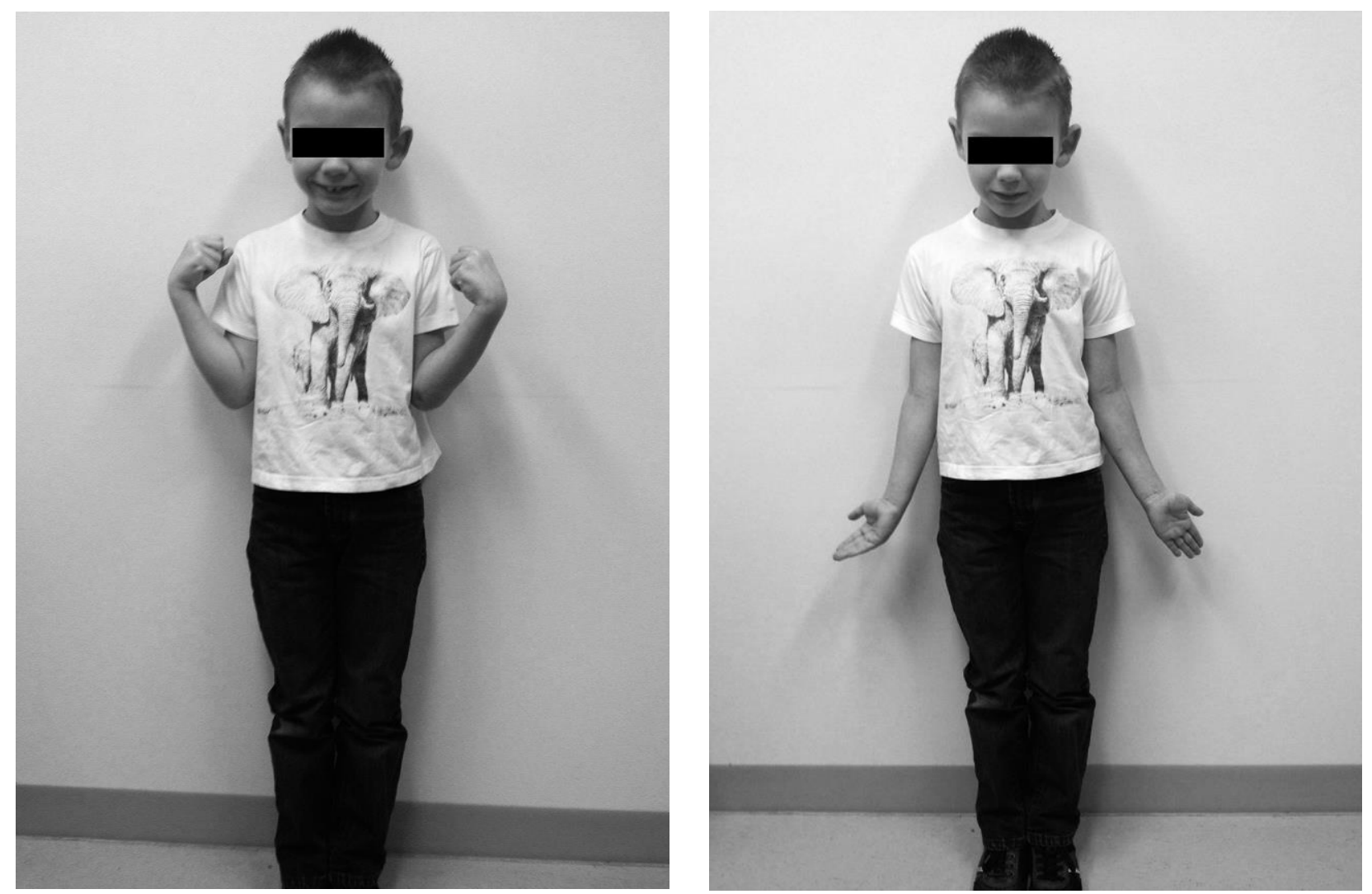

Figuur 5. Range of motion drie maanden postoperatief: flexie (links) en extensie (rechts). 


\section{Literatuur}

1. Cheng J, Ng B, Ying S, Lam P. A 10-year study of the changes in the pattern and treatment of 6,493 fractures. J Pediatr Orthop. 1999. p. 344-50.

2. Farnsworth C, Silva PD, Mubarak SJ. Etiology of supracondylar humerus fractures. J Pediatr Orthop. 1998 Jan-Feb; 18(1):38-42.

3. Gartland JJ. Management of supracondylar fractures of the humerus in children. Surg Gynecol Obstet. 1959 Aug;109(2):145-54.

4. Tomaszewski R, Gap A, Wozowicz A, Wysocka P. Analysis of early vascular and neurological complications of supracon- dylar humerus fractures in children. Polish Orthop Traumatol. 2012;77:101-4.

5. Vincelet Y, Journeau P, Popkov D, et al. The anatomical basis for anterior interosseous nerve palsy secondary to supracondylar humerus fractures in children. Orthop Traumatol Surg Res. 2013 Sep;99(5):543-7

6. Ramachandran M, Birch R, Eastwood DM. Clinical outcome of nerve injuries associated with supracondylar fractures of the humerus in children: the experience of a specialist referral cen- tre. $\mathrm{J}$ Bone Joint Surg Br. 2006 Jan;88(1):90-4.

7. Ozkoc G, Gonc U, Kayaalp A, et al. Displaced supracondyl- ar humeral fractures in children: open reduction vs. closed reduction and pinning. Arch Orthop Trauma Surg. 2004 Oct;124(8):547-51.

8. Brauer CA, Lee BM, Bae DS, et al. A systematic review of medial and lateral entry pinning versus lateral entry pinning for supra- condylar fractures of the humerus. 2007;27(2):181-6. 9. Pretell-Mazzini J, Rodriguez-Martin J, Andres-Esteban EM. Does open reduction and pinning affect outcome in seve- rely displaced supracondylar humeral fractures in children? A systematic review. Strategies Trauma Limb Reconstr. 2010 Aug;5(2):57-64.

10. Aktekin CN, Toprak A, Ozturk AM, et al. Open reduction via posterior triceps sparing approach in comparison with closed treatment of posteromedial displaced Gartland type III supracondylar humerus fractures. J Pediatr Orthop Part B. 2008 Jul;17(4):171-8.

11. Chen RS, Liu CB, Lin XS, et al. Supracondylar extension frac- ture of the humerus in children using a u-shaped plaster slab with the elbow in full extension. J Bone Joint Surg Br. 2001 Aug;83(6):883-7.

12. Fowler TP, Marsh JL . Reduction and pinning of pediatric supra- condylar humerus fractures in the prone position. J Orthop Trauma. 2006 Apr;20(4):277-81.

13. Cheng J, Lam T, Maffulli N. Epidemiological features of supra- condylar fractures of the humerus in Chinese children. J Pediatr Orthop. 2001;10:63-7. 
14. Parmaksizoglu AS, Ozkaya U, Bilgili F, Sayin E, Kabukcuoglu Y.Closed reduction of the pediatric supracondylar humerus fractures: the "joystick" method. Arch Orthop Trauma Surg. 2009 Sep;129(9): 1225-31.

15. Novais EN, Andrade MA, Gomes DC. The use of a joystick tech- nique facilitates closed reduction and percutaneous fixation of multidirectionally unstable supracondylar humeral fractures in children. J Pediatr Orthop. 2013 Jan;33(1):14-9.

\begin{abstract}
Closed reduction and percutaneous pinning have become the standard method of treatment of displaced supracondylar humeral fractures in children. Precise anatomical reduction is crucial in order to get good treat- ment results. Traditional closed reduction can be challenging for these multidirectional, unstable fractures. Our goal is to point out a closed reduction method for the treatment of displaced supracondylar humeral fractures using a temporal Kirschner-wire which is positioned in the proximal humeral fragment. This tech- nique could reduce the amount of conversions to open reposition.
\end{abstract}

